\title{
CLINICAL ACCOMPANIMENT LET THE VOICE OF THE PRE-GRADUATE STUDENTS COUNT
}

\author{
N.S. Kgafele \\ University of Pretoria \\ sabikga@hotmail.com
}

\section{Coetzee}

University of Pretoria

isabel.coetzee@up.ac.za

\section{T. Heyns}

University of Pretoria

tanya.heyns@up.ac.za

\section{ABSTRACT}

Nursing is a practice-based profession and it is essential that pre-graduate students are socialised in the clinical learning environment from the beginning of their training. Consequently, clinical accompaniment is regarded as a vital component of a nursing programme to offer the necessary support to pregraduate students. The objective of this study was to explore and describe pregraduate students' view regarding the clinical accompaniment they received as part of the clinical component of the four-year programme. In this study a qualitative, contextual, explorative, descriptive and interpretive research design was used to explore and describe pre-graduate students' views of clinical accompaniment as part of the clinical component of the four-year programme. The findings of the study were based on how students viewed clinical accompaniment and they revealed: inadequate support from nurse educators, lack of resources, inadequate support from registered nurses, and disregard for student status. Evaluating the clinical accompaniment of pre-graduate students utilising a positive approach of Appreciative Inquiry (Al), gave students the opportunity to give inputs into the aspect that works well (positive) as well as

\section{UNISA $\cong$}


the challenges (negative aspects) as perceived by pre graduate students. The inputs were utilised to draft an action plan to move towards excellence in clinical accompaniment.

Keywords: clinical facilitator, clinical learning environment, one-year post-graduate diploma, operating theatre nursing students

\section{INTRODUCTION}

The South African Nursing Council (SANC) Regulation R425 (1985) stipulates that in a Nursing Education Institution (NEI) providing the four-year comprehensive nursing programme should also provide pre-graduate students with both classroom (theoretical) and clinical (practical) learning opportunities. The clinical component, which is facilitated through clinical accompaniment by the nurse educator, takes place in the Clinical Learning Environment (CLE). Nursing is practice based and this provides the opportunity for students to apply cognitive, psychomotor and affective skills and to enhance correlation of both theory and practice (Chan, 2002:1 \& Kotzé, 2008:192). In addition, Kotzé (2008:198) indicates that clinical accompaniment of pre-graduate students plays a fundamental role in promoting self-empowerment. Nurse educators must be present in the clinical learning environment to provide their students with support and to assist with learning experiences (Kotzé, 2008:34; Sundler et al., 2013:665). Clinical accompaniment in the education and training of pre-graduate students provides the experiential foundation for the knowledge, skills, and values to be consolidated and applied in practice (Moleki, 2008:1).

Kotzé (2008:34) emphasises the presence of nurse educators in the CLE in order to provide their students with support and to assist with the learning experience. Clinical placement provides the pre-graduate students with optimal opportunities to observe role models, to learn, practise and reflect on what is seen, heard, sensed and done. The support from the nurse educator during clinical accompaniment cannot be overemphasised (Sundler et al., 2013:665). In addition, the CLE enhances pre-graduate students' opportunity to develop the required attitudes, competence, interpersonal skills, critical thinking and clinical problem-solving abilities (Chan, 2002:666). It is imperative to "...improve programme (theory and practical) effectiveness and demonstrate accountability..." through continuous programme evaluation, as these will ensure continuous excellence in nursing education and practice (Dillard \& Sitkberg 2009:86; Papathanasiou, Tsaras \& Sarafis, 2014:57).

\section{PROBLEM STATEMENT}

The clinical component of the comprehensive four-year nursing programme forms the most significant part of the nursing education curriculum, as it provides the students with opportunities to learn and apply theory to practice and to be socialised 
into the expectations of the employment (clinical) setting (Stokes \& Kost, 2009:283; Papathanasiou, Tsaras \& Sarafis, 2014:57).

As a nurse educator, the researcher's day-to-day interactions with pre-graduate students in the CLE as well as students' feedback, the researcher realised that students do not all view the clinical accompaniment they received in a positive manner. Some students gave positive feedback, whilst others identified challenges with the clinical accompaniment. At the specific Nursing Education Institution (NEI) where the researcher is a nurse educator, CLE as part of the clinical component of the four-year comprehensive programme had not been evaluated formally for the past ten years. Based on feedback the researcher received from pre-graduate students pertaining to clinical accompaniment received, there is a desperate need to formally evaluate clinical accompaniment as part of the clinical component of the four-year comprehensive programme. This statement is supported by Armstrong (2009: 177) when she asserts that we (lecturers) need not only evaluate whether the pre-graduate students have reached the desired competencies and learning outcomes, but also to evaluate the effectiveness of the programme. In order to maximise the students' clinical learning experience, the researcher therefore wished to explore and describe pre-graduate students' current views based on their experiences pertaining to clinical accompaniment they received from nurse educators. Based on the findings of the study, the researcher made recommendations to enhance clinical accompaniment and work towards educational excellence in this unique learning environment.

\section{Aim of the study}

The overall aim of the study was to explore and describe clinical accompaniment as part of the clinical component of the four-year comprehensive programme by means of Appreciative Inquiry (AI).

\section{Research objectives'}

The objective of the study was to explore and describe the views of pre-graduate students regarding the clinical accompaniment they received, as part of the four year comprehensive programme.

\section{DEFINITION OF KEY CONCEPTS}

Nursing education institution (NEI). The Nursing Act, 33 of 2005 (2005:6) defines a nursing education institutionas any nursing education institution accredited by the SANC. According to SANC R425 (1), a nursing college means a postsecondary educational institution which offers professional nursing education at basic and post-basic level where such nursing education has been approved in terms 
of section 15(2). For the purpose of this study the NEI is in Gauteng and the students were registered for the four year comprehensive programme.

Pre-graduate programme. A programme is "a planned series of events" (Collins English Dictionary, 2005:651). In this study the pre-graduate programme meant the comprehensive four-year nursing programme. The four-year diploma in comprehensive nursing allows pre-graduate students who have successfully completed the programme to register as nurses (General, Psychiatric and Community) and midwives with the SANC (R425, 1985).

Pre-graduate student. Kotzé (2008:187) defines a nursing student asa person "who enters the basic nursing education programme, and has successfully completed 12 years of schooling, meets the requirements for higher education at an approved school of nursing".In this study a nursing student referred to a second, third and fourth-year pre-graduate student enrolled for the comprehensive four-year nursing programme at the selected NEI in Gauteng.

\section{CONTRIBUTION TO THE FIELD OF THE STUDY}

The results from this study enabled the researcher to make recommendations to enhance clinical accompaniment of pre-graduate students, based on the views of the students. The study gave students an opportunity to give inputs regarding the positive aspects pertaining to clinical accompaniment as well as the challenges they experienced. The value of the inputs from the students confirmed the importance of listening to the voice of the "customer", The pre-graduate student can be viewed as the "customer" of the educator. On the contrary, programmes are sometimes evaluated without the students' inputs. Furthermore, this study gave educators the opportunity to reflect on the students' feedback and use it to plan strategies for enhancing clinical accompaniment so as to meet the needs of the students and address challenges pertaining to clinical accompaniment received.

\section{RESEARCHMETHODS AND DESIGN}

In this study the researcher utilised the Appreciative Inquiry (AI) approach to evaluate clinical accompaniment as part of the clinical component of the comprehensive four year programme in a positive way. In view of Havens, Wood and Leeman (2006:464) $\mathrm{AI}$ is defined as a "...philosophy and methodology for promoting change through creating meaningful dialogue, inspiring hope and inviting action..." Members are engaged in practices or organizational settings based on appreciation of what was done, and identify wishes of what should be. AI is utilised as an approach that has moved away from the traditional problem-based approach to a more affirmative approach, whereby organisations (NEI) seek to discover the potential for growth 
and transformation from the employees (Nurse educators) (Cooperrider \& Whitney, 2000:3; Shendell-Falik, Feinson \& Mohr, 2007: 96 \& Lind \& Smith, 2008: 31). Student where provided an opportunity to appreciate the aspect pertaining to clinical accompaniment they valued most and to identify the wishes (reflected the challenges) they have regarding optimal clinical accompaniment. The information gathered from the students gave the nurse educators' an opportunity to gain insight on which aspects should be built on (positive aspects) and actions plan were made to address the challenges regarding clinical accompaniment. Stefaniak (2007:43) maintains that AI is a philosophy, a strategy and a storytelling method in the belief that a positive approach to problem solving, culture change and strategic planning are energizing and long-lasting.

The researcher wished to explore what is viewed as the best experiences of pre-graduate students regarding clinical accompaniment, address challenges pertaining to clinical accompaniment, and make recommendations to move clinical accompaniment towards excellence and enhance the clinical learning experiences of pre-graduate students.

\section{DATA COLLECTION METHODS}

Data was collected by means of a self-report interview guide The researcher used a semi-structured approach focusing on the AI process, which is collaborative, thereby giving the participants enough scope to answer the way they felt was useful, rather than the way the researcher predetermined (Reed, 2007:128). Open-ended questions designed based on the "4-Ds" namely; Discovery, Dream, Designing and Delivery phases of the AI process were used to inquire about the participants' overall experiences as suggested by (Reed, 2007:123).

The researcher utilised a self-report interview guide to collect data because of the large number (approximately 220) of participants (nursing students) involved. This method was convenient in terms of saving time and giving all the participants an opportunity to participate in the study and to give inputs relating to the clinical accompaniment they received as students working in the CLE. The researcher developed the semi-structured self-report questionnaire for participants and included a participant information leaflet explaining the purpose of the study and containing instructions for completing the self-reported interview guide as suggested by (Polit \& Beck, 2008:425; Reed, 2007:128).

The researcher personally collected the data and addressed each year group $\left(2^{\text {nd }}\right.$ to $4^{\text {th }}$ ) individually, at a time when they were at the NEI for the theoretical component of the programme. This approach was most convenient and had the advantages of maximising the number of completed self-reported interview guides and allowing 
the researcher to clarify any possible misunderstanding (Polit \& Beck 2008:430). The researcher obtained permission from the lecturer to use approximately forty five (45) minutes of the lecture time to allow the students to complete the self-reported interview guides. The researcher provided an overview of the study to the pregraduate students before giving them time to complete the self-reported interview guides. During the presentation the aim and objectives of the study were explained to the students as well as an overview of AI. The researcher explained what was expected of the students and how the process of data collection would take place. The researcher emphasised that participation in the study was voluntary and would have no impact on their academic performance.

The self-reported interview guides were handed out to the participants and they were given time to complete and sign the informed consent forms. The participants deposited the completed consent forms in a provided sealed container. Thereafter the students completed the self-reported interview guides and deposited them in a separate sealed container. Separate sealed containers ensured that no correlation could be made between the self-reported interview guides and the participants' informed consent. The researcher provided separate sealed containers with a narrow one-way opening to ensure confidentiality for posting the self-report interview guides after completion. After completing the self-report interview guides, the sealed containers were personally collected by the researcher. The containers were personally opened by the researcher after everyparticipant had posted the self-reported interview guides.

\section{Recruitment procedures}

The accessible population in this study included all the second, third and fourthyear pre-graduate students in the specific NEI. Table 1 indicates the number of pregraduate students accessible for the study.

Table 1: Accessible population

\begin{tabular}{|l|l|}
\hline YEAR OF STUDY & NUMBER OF STUDENTS \\
\hline Second year & 90 \\
\hline Third year & 80 \\
\hline Fourth year & 47 \\
\hline
\end{tabular}

The accessible population consisted of $\mathbf{2 1 7}$ senior pre-graduate nursing students.

\section{Data analysis}

According to Polit and Beck (2012:725) data analysis is the systematic organisation and synthesis of research data. In qualitative research data analysis begins during data 
collection, and continues until the end of the study. The data collected in this study was non-numerical, in the form of written narratives on the self-reported interview guides.Data in qualitative research is non-numerical; it is usually in the form of written words or videotapes, audiotapes and photographs (Brink et al., 2012:201). Analysing qualitative data therefore involves an examination of words, rather than numbers, that are considered in quantitative studies (Brink et al., 2006:184). In this study, data were analysed using content analysis, which is designed to classify the words in a text into a few categories (Brink et al., 2012:201).

To analyse data, the researcher used Tesch's (1990) eight-step method of data analysis (Creswell 2003:191) as follows:

Step 1: Data was organised and prepared for analysis. This involved sorting and arranging the data from the self-report interview guides into different types, depending on the sources of information.

Step 2: The researcher took all the AI interview guides and read through the information to obtain a sense of the whole and to reflect on its overall meaning. These included the ideas and impressions from the participants, overall depth, credibility and use of information. The underlying meaning was identified in the individual interview guide. Themes, categories and sub categories that emerged were written down. Data was grouped under different categories as codes and analysis was enhanced. The participants' direct quotes were used as units of analysis.

Step 3: The detailed analysis started with a coding process. The categories were utilised as codes. A code is a symbol or abbreviation used to classify words or phrases in the data (Burns \& Grove, 2007: 522). Creswell (2003: 192) defines coding as "the process of organizing the material into 'chunks' before bringing meaning to those chunks". Data is integrated or linked through conceptualisation of grouped data into a hierarchy of definite categories and subcategories (Schneider, Whitehead \& Elliot, 2007: 143).The researcher started with the data analysis once all the completed self-report interview guides were collected. Brink et al., (2006:184) state that the researcher can check the trustworthiness of the coding process by having another person encoding the same data.In this study, the researcher appointed a co-coder to verify the data initially analysed by the researcher.The researcher made a list of all the topics from the documents. Clustered similar topics and formed these topics into columns to indicate major topics, unique topics, and leftovers.

Step 4: The topics were then abbreviated as codes next to the appropriate segments of the text. The coding process was used to generate a description of the setting or people as well as categories or themes. This involved a detailed rendering of information about people, places, or events in a setting. The researcher utilized the information on the self-reported interview guides to develop themes, categories and sub-categories pertaining to clinical accompaniment. 
Step 5: The most descriptive wording for the topics was found and turned into categories. The list of categories was reduced by grouping topics that related to each other. This step advances how the themes will be represented in the qualitative narrative.

Step 6: A final decision on the abbreviation for each category was made and then the codes were arranged alphabetically.

Step 7: The data material belonging to each category was assembled in one place and preliminary analysis performed.

Step 8: The existing data was re-coded by the co-coder. The final step in data analysis involves making an interpretation or meaning of the data. It involves feedback on the outcome of the study, or the lessons learned. It could also be a meaning derived from a comparison of the findings with information gleaned from the literature. It can also suggest new questions that need to be posed.

\section{CONTEXT OF THE STUDY}

The setting was a government funded NEI in Gauteng. Furthermore, the pregraduate students are placed in the CLE where they gain clinical experience and attain specific clinical learning opportunities. The CLE was the academic hospital where the pre-graduate students interchange through medical and surgical wards, as well as casualty, operating theatres and intensive care departments.

\section{RESULTS}

Table 2: Summary of the results

\begin{tabular}{|l|l|}
\hline Themes & Categories \\
\hline Nurse educator support & Availability of nurse educator \\
& Supportive attitude \\
& Supportive interventions \\
& Practical demonstrations \\
& Present first day in the CLE \\
& Bridge gap between theory and practice \\
\hline Professional nurses support & Positive attitude towards students \\
& Create learning opportunities \\
& Effective orientation \\
& Commitment to teaching \\
\hline Professional acknowledgment & Acknowledgement of student status \\
& Respectful treatment \\
\hline
\end{tabular}




\section{Ethical considerations}

Ethical clearance was obtained from the ethics committee of the Faculty of Healthcare Sciences, University of Pretoria as well as from the ethics committee of the Nursing Education institution where the researcher conducted the study. Ethics clearance number: S133/2011.

\section{Data protection}

All data collected during this study, self-reported interview schedules as well as field notes, will be kept in a locked cupboard in the researchers office for a time frame of 15 years, as stipulated by the research ethics committee.

\section{Trustworthiness}

Trustworthiness is "the degrees of confidence qualitative researchers have in their data, and is assessed using the criteria of credibility, dependability, confirmability, transferability, and authenticity" (Polit \& Beck, 2008:768). The four strategies for trustworthiness are credibility, transferability, dependability and confirmability (Polit \& Beck, 2008:544; Lincoln \& Guba, 1985:301). These strategies were applied as follows in this research:

\section{Credibility}

Credibility is ensured by "remaining with participants during data collection, and having independent colleagues review, validate and verify the researcher's interpretations andconclusions to ensure that the facts have not been misconstrued" (Brink et al., 2012: 172).

Lincoln and Guba (1985:301) state that credibility can be accomplished through prolonged engagement and peer review.

\section{Dependability}

Dependability is similar to reliability in qualitative research, and refers to the stability of data over time and conditions (Polit \& Beck, 2012:172). The researcher made use of an enquiry auditor to follow the process and procedures used during the study in order to determine whether the processes were acceptable (Brink et al., 2012:172). The co-coder was appointed to do the coding together with the researcher. In addition, raw data were left for anyone to conduct a data audit should they wish to do so. 


\section{Transferability}

Transferability refers to the extent to which the findings can be transferred to or applied in other settings (Polit \& Beck, 2012:745). There is no single or "true" interpretation in the naturalistic paradigm. The researcher should provide thick vivid descriptions of the research process so that consumers can evaluate the applicability of the data to other contexts (Polit \& Beck, 2012:745). The study was limited to a specific NEI in Gauteng, but the researcher compiled a detailed report to provide other researchers with data to use in order to replicate the study for other settings

\section{Confirmability}

Confirmability is concerned with establishing that the data represents the information provided by participants and that the interpretations are not figments of the inquirer's imagination (Polit \& Beck, 2012:723; Brink et al., 2012:119). Lincoln and Guba (1985:299) refer to confirmability as "a strategy to achieve neutrality" and neutrality as "a criterion used to establish the degree to which the findings of an inquiry were not influenced by the researcher, and could be confirmed by an independent inquirer". To ensure confirmability, the researcher left an audit trail of the full description of the research process.

\section{Discussion and literature control}

\section{Nurse educator support}

Although the participants indicated their appreciation for the support they received from their nurse educators in the previous section, they also wished that this support could be extended to all the nurse educators and included frequency of availability

The following quotations support the derived theme "nurse educator support" from the data analysis.

Our lecturers (nurse educators) had a lot to deal with but they managed to create time to come and assist us with areas where we could not apply theory to practice.

My wish is for our lecturers (nurse educators) to visit the clinical areas more often.

Quinn and Hughes (2007:377) identify the nurse educator as a mentor and a role model responsible for giving support, facilitating the learning experiences, undertaking clinical teaching and assessing the student's practice. Kotzé (2008: 200) maintains that in order to develop a functional relationship, the nurse educator should be continuously available to give helpful and supportive guidance to the nursing student in the clinical learning area, this is supported by Bjork et al. (2014:2963). Pre-graduate students perform better in an environment where they feel accepted 
and their contributions are appreciated and this increases their morale (Stokes \& Kost, 2009:283). The following categories and sub-categories emerged relating to the findings and supportive literature based on nurse educator support.

\section{Availability of nurse educators}

The majority of the participants wished the nurse educators could be at the CLE all the time and not only during assessments. Some of the participants wished nurse educators could at least visit the CLE at least on a weekly basis. Some of the participants indicated the challenges they faced in the CLE and believed these could be alleviated if they got support from the nurse educators.

The presence of the nurse educators in the CLE helped to ease the frustrations and uncertainties of a new environment.

Nurse educators should visit the CLE on weekly basis. The hospital staff tends to intimidate us sometimes.

... also think accompaniment should be done on a weekly basis.

The presence of a nurse educator in the CLE plays a pivotal role in giving the necessary support to pre-graduate students (Bjork et al., 2014:2963). Though it is also the responsibility of the nursing unit manager to support and do accompaniment, some students appreciate the presence of the nurse educator for guidance (Kotze 2008: 200, Papathanasiou, Tsaras \& Sarafis, 2014:59). The South African Nursing Council (R425, 1985) stipulates that the nurse educator should spend at least 30 minutes per week with a pre-graduate student in the CLE.

Meyer and van Niekerk (2008:92) maintain that active accompaniment on the part of the nurse educator is extremely important, this is supported by Sundler et al. (2014:665) they adopted the approach of a "preceptor-a-day" where the student will be allocated a preceptor for a day to support the student in the CLE. In Italy, Perli and Brugnoli (2009: 889) found that the participants perceived that the presence of the clinical tutor contributed to students having an innovative learning environment.

\section{Supportive attitude}

The participants indicated satisfaction with the support they received from their nurse educators in the CLE. They noted that through support and guidance they were able to build confidence in their practice, learn the communication skills and how to conduct themselves in front of the patients and the rest of the hospital personnel.

Learning how to communicate with a patient while busy with a procedure was great, and this happened with the support from the nurse educator. 
The positive attitude of the nurse educator contributes to the development of the pregraduate student because an environment that is conducive and welcoming is able to yield healthy minds. Chisane (2009:18) states that an environment that is conducive to learning is a vital component of effective student nurse accompaniment. Meyer and van Niekerk (2008: 107) maintain that the nurse educator's attitude towards pregraduate students and the staff affects the personal interactions that are established in the educational environment.

\section{Supportive interventions}

The participants indicated some of the supportive and helpful interventions by the nurse educators during their clinical accompaniment such as being there for them during their practice helped a lot.

Clinical accompaniment provided by the lecturer (nurse educator) when I did care of the deceased was most comforting and supportive ...

Pre-graduate students learn the clinical skills in order to be able to interact with patients in the CLE. The role of the nurse educator is to facilitate the mechanisms that will enhance critical thinking, problem solving and care for diverse clients in a safe and non-threatening environment (Stokes \& Kost, 2009: 322; Papathanasiou, Tsaras \& Sarafis, 2014:57).

\section{Discussion sessions}

The participants wished there were sessions for discussing diseases and patients with the nurse educators during their clinical placement. Some of the participants indicated they wished the hospital provided a venue for holding discussions or presentations with nurse educators as it happened with the doctors.

I wish there can be sessions to discuss some diseases and share ideas.

Ehrenberg and Häggblom (2006:71) found that students perceived regular meetings with other students for reflection and relations with the preceptor as effective and enhancing their learning. Mongwe (2007:181) asserts that discussions in the clinical field could act as a vehicle to reflect on student nurse achievements in terms of clinical learning. This is supported by Sundler et al. (2014:665).

\section{Practical demonstrations}

The majority of the participants indicated their wish to have at least a day set aside at the CLE for practical demonstrations so that they could practise. Clinical skills can only be mastered if they are repeatedly practised. Some participants indicated they 
wished nurse educators would lead by example and demonstrate some procedures in the wards.

Students wish there can be a clinical teaching day for them to practise and demonstrate back.

It is the responsibility of nurse educators to demonstrate clinical skills to pre-graduate students before they practise in the wards (Quinn \& Hughes, 2007:379). According to Meyer and van Niekerk (2008:168), students are guided towards quality nursing care, and this is accomplished by demonstration of nursing procedures, and clinical accompaniment until they execute procedures correctly. In support of the previous authors Hodson-Carlten (2009: 304) emphasise that thorough preparation of pregraduate students for clinical practice is a critical role in nursing education. In a study conducted by Sundler et al. (2014:665) an approach of a "preceptor-a-day" had very positive outcomes where students' in the CLE were allocated a preceptor for the day to assist/support them in all activities.

\section{Presence of nurse educator the first day in practice}

Although the participants noted that some of the nurse educators were present in the CLE on their first day of clinical placement, they also indicated that the participation of nurse educators during orientation on the first day was not enough. The participants indicated they wished their nurse educators could be present at the CLE during their orientation on the first day at the CLE. This would help alleviate anxiety.

It was my first day at the hospital where I was accompanied by my nurse educators. They made it easier for me to adapt to the new environment that I was never exposed before.

Chesser-Smith (2005:321) points out that when anxiety is high, an individual is immobilised, perceptions are narrowed and learning is impeded. In a study conducted by, Mongwe (2007:166) participants indicated they expected the clinical tutor to welcome them in the CLE and know their whereabouts all the time. Similarly the study conducted by Chesser-Smith (2005:323) revealed that students received a positive welcome on their first day and this had a positive impact on their selfesteem.

\section{Bridging the gap between theory and practice}

The participants indicated they wished there could be proper correlation of theory with practice, as some procedures were not done the way they were demonstrated at the CLE.

We wish to see a universal standard of doing procedures. It is sometimes confusing for a student to get different views from qualified nurses of the same qualification. 
They must also teach the students exactly what is done in clinical because sometimes what they teach them is not what is done practically.

In a study on integrating theory and practice in problem-based learning in clinical education, Ehrenberg and Häggblom (2006:72) found that students perceived regular meetings with other students and the preceptor for reflection as very effective, because they were integrating theory and practice in their sessions. Papastavrou, Lambrinou, Tsangari and Saarikoski (2009:177) maintain that nursing education is characterised by a close relationship between theory and practice, meaning that nursing cannot be learnt through either theory or practice alone. Mongwe (2007:149) states that participants articulated learning in the clinical field as "doing the right thing".

\section{Professional nurse support}

Participants indicated they need the support of the professional nurses during placement in the clinical learning environment.

I wish the hospital can appoint professional nurses that can guide students in the clinical environment full time.

When allocated to the CLE pre-graduate students are handed over to professional nurses for clinical practice, and according to Bruce, Klopper and Mellish (2011: 256) the main function of the professional nurse is to render quality patient care, and they must ensure that those caring for the patients are capable of providing it. Therefore the authors emphasise that the professional nurse has a moral duty to teach, mentor and supervise pre-graduate students. In addition, Quinn and Hughes (2007: 346) advocate that professional nurses should be approachable and helpful to pre-graduate students. They further advocate that they should provide them with support. The above mentioned is reinforced by Sundler et al. (2014:665) who support the importance of a preceptor in the CLE on a daily basis.

\section{Positive attitude towards students}

Most of the participants indicated they wished to be accepted and respected as individuals. Nursing personnel should be patient with students and be willing to teach them, and this would boost their morale.

"...I wish all permanent nursing personnel would treat us with respect and take part in teaching us things that we must know..."

Hauer et al. (2014:442) is of the opinion that the clinical supervisor should have a positive and supportive attitude towards the student. According to Andrews et al (2005:863), positive interpersonal relationships between students and ward staff is critical since the students' desire for support, respect and acceptance from more 
experienced colleagues is of major importance. Quinn and Hughes (2007:346) concur, adding that qualified staff should be approachable and helpful to students and provide support as necessary. Levett-Jone and Lathlean (2007:107) found that students described how difficult it was to be motivated and enthusiastic when their placement experiences had been overshadowed by alienation from the nursing team.

\section{Create learning opportunities}

The participants indicated they were eager to learn and wished the professional nurses would create opportunities for learning, such as seminars on aspects like good health, illness, general hospital management and etiquette. They also indicated their wish to work co-dependently with the professional nurses and doctors especially during ward rounds, as they believed it could broaden their knowledge. The participants indicated they preferred to be given an opportunity to learn without being humiliated.

“...Students should be allowed to work co-dependently with RNs and doctors enabling us to broaden our knowledge without being humiliated..."

Meyer and van Niekerk (2008:172) recommend that pre-graduate students should be allocated to the CLE where there are professional nurses to guide them, and on that note learning opportunities should be should be provided for them. In addition, Bruce et al.(2011:256) point that the professional nurse may make use of the "teachable moment" or either formal or informal way of guiding and teaching pre-graduate students. Muller (2011:335) furthermore encourages pre-graduate students to prove that they are ready to learn by displaying the necessary interest, motivation and sense of responsibility.

\section{Professional acknowledgement}

The participants indicated they wished to be acknowledged as students by the members of the multi-professional health team.

"...All students to be treated as students in the clinical areas and not as the workforce..."

Pre-graduate students wish to be acknowledged as learners and not as members of the health team as supported by Quinn and Hughes (2007: 341) when asserting that the presence of the pre-graduate student in the workplace is on the basis of a placement for practice. According to Kotzé (2008: 186) the pre-graduate students "... do not form part of the essential nursing staff complement to keep a health service functioning, but are afforded practice learning as members of the nursing an healthcare teams..."

Mongwe (2007:341) and Quinn and Hughes (2007: 341) indicate that the presence of a pre-graduate student in the workplace is on the basis of a placement and not as part of the workforce of the clinical setting. 


\section{Respectful treatment}

Students wish to be treated with respect and dignity. The majority of the participants indicated they wished to be treated with respect and that some nurses should improve their attitude towards students. Some of the participants indicated they were adults despite the fact that they were students. Another important wish of the participants was the full involvement of the college in student matters by liaising with the hospital on a regular basis.

"...I am a student, an adult and a human being, so I desire to be treated with respect..."

In Australia, Chan (2004:8) found that students' level of satisfaction was high when they were treated with respect, especially when they were included as part of the working team. Similarly, in Hong Kong Chan and Ip (2006:682) found that even though students were already receiving a good amount of support, respect and recognition in the CLE, they demanded more attention in this area as they saw the utmost benefit to their clinical learning. Hauer et al. (2014:442) as well as Muller (2011: 334) emphasises that mutual respect and trust is vital in the relationship between the student and the clinical facilitator.

\section{Limitations}

A limitation of qualitative studies is their lack of generalisability of the conclusion (Holloway \& Wheeler, 2002:35). The purpose of this study was to explore and describe pre-graduate students' views of the clinical accompaniment they received in the CLE. The main limitation of this study was that it was conducted at one specific NEI in Gauteng and therefore cannot be generalised to all NEI institutions offering the four-year comprehensive programme in the Republic of South Africa.

\section{Recommendations}

Based on the participants' views of the clinical accompaniment they received as part of the four year comprehensive programme the following recommendations were made:

\section{Nurse educators in the clinical learning area}

- There should be a nurse educator at the CLE on a daily basis to meet the needs of the students.

- To increase the number of nurse educators in the CLE on a daily basis, it is recommended that more clinical facilitators' posts be made available. 
- The nurse educators should at least visit the clinical learning area on a weekly basis to support, identify the needs and give guidance during clinical practice.

- The NEI should recruit more nurse educators to ensure that there is adequate staff (human resources) for clinical accompaniment.

- There should be a planned schedule for the nurse educator-student contact sessions at the CLE whereby students will be able to prepare themselves for such sessions.

- More time should be allocated for clinical practice. It is recommended that a clinical practice day should be scheduled at least once a week on pre-graduate students' rotation roster.

- Specific nurse educators should be allocated to specific wards in the CLE. That will enable nurse educators and professional nurses to build up professional relationship and this, in turn, will enhance collaboration from the professional nurses in terms of education and training of students.

\section{Professional nurses}

- Professional nurses should revisit their role towards students on training.

- Professional nurses from the CLE should be invited to monthly clinical meetings.

- The learning outcomes of the students should be clearly communicated to the professional nurses, so that students are delegated tasks within their scope of practice.

- Stakeholders should be involved in the planning of placement of pre-graduate students in the CLE.

\section{Resources}

- Students should be provided and assisted with transport from their institution residence to the allocated hospital.

- Allocation of a discussion room for pre-graduate students and their nurse educators within the CLE should be utilised during allocated clinical days.

- Provision of adequate and serviceable equipment for practice.

- Provision of library facilities with accessible internet facilities for students. The internet facility should be extended to after hours to accommodate students from work and theoretical classes.

- Academic hospitals should take cognisance of the students in training when they budget for equipment. 
- Pre-graduate students should be placed in other busy CLEs such as provincial hospitals and clinics around Gauteng to gain more exposure.

\section{Future research}

The researcher recommends further research should be undertaken on the following topics (utilising the AI):

- An evaluation of the views of nurse educators and professional nurses on clinical accompaniment

- An exploration of pre-graduate students' views of the CLE.

- An investigation into the utilisation of retired nurses in the clinical accompaniment of pre-graduate students

\section{CONCLUSION}

The findings of this research revealed the participants' positive and negative experiences in the CLE pertaining to clinical accompaniment. The pre-graduate students wish for the ideal clinical environment, and the challenges pertaining to clinical accompaniment were explored and defined. Based on the findingsthe researcher was able to make recommendations to enhance clinical accompaniment of the pre-graduate student when they rotate through the clinical learning environment as part of the clinical component of the four year comprehensive programme.

\section{REFERENCES}

Andrews, GJ, Brodie, DA, Andrews, JP, Hillan, BG, Wong, J \& Rixon, L. 2005. Professional roles and communications in clinical placements: a qualitative study of pre graduate students' perceptions and some models for practice. International Journal of Nursing Studies, 43(2006):861-874.

Armstrong, S. 2008. The concept of quality nursing education. In Nurse educators' guide to management, edited by W Kotzé. Pretoria: Van Schaik:.132-140.

Bjork, IT, Brenton, K, Brynildsen, G \& Hestetun, M.2014. Nursing students' perseptions of their clinical learning environment in placements outside traditional hospital settings. Journal of Clinical Nursing,23,2958-2967.

Brink, H, van der Walt, C \& van Rensburg, G. 2012.Fundamentals of research methodology for health care professionals. $3^{\text {rd }}$ edition. Pretoria: Juta.

Burns, N \& Grove, SK. 2005.The practice of nursing research: conduct, critique, and utilization. $5^{\text {th }}$ edition. St Louis: Elsevier Saunders. 
Chan, DSK. 2002. Development of the clinical learning environment inventory: using the theoretical framework of learning environment studies to assess pre-graduate students' perceptions of the hospital as a learning environment. Journal of Nursing Education. 42(2):69-75.

Chesser-Smyth, PA. 2005. The lived experiences of general student nurses on their first clinical placement: a phenomenological study. Nurse Education in Practice, 5:320-327.

Creswell, JW. 2003. Research design: Qualitative, Quantitative, and Mixed methods approaches. $2^{\text {nd }}$ edition. London: Sage.

Collins English Dictionary. 2005. Discovery edition. Glasgow: HarperCollins.

Cooperrider, DL \& Whitney, D. 2000. A positive revolution in change: Appreciative Inquiry. http://appreciativeinquiry.case.edu/uploads/whatisai.pdf (Accessed 20 March 2010).

De Vos, AS, Strydom, H, Fouche, CB \&Delport, CSL. 2013. Research at grass roots for the social sciences and human service professions. 4th edition. Pretoria: Van Schaik.

Ehrenberg, AC \& Häggblom, M. 2006. Problem-based learning in clinical nursing education: integrating theory and practice. Nurse Education Practice, 7:67-74.

Failender, JM \&Shafranske, P. 2003. Clinical placement features. Nursing Standards, 30: 1-24.

Grove SK, Burns N \&Gray JR. 2013. The practice of nursing research.Appraisal, Synthesis, and Generation of Evidence.Seventh Edition. Missouri: Elsevier.

Hauer, KE, ten Cate, O, Boscardin, C, Irby, DM, Iobst, W \& O 'Sullivan, PS. 2014. Understanding trust as an essential element of trainee supervision and learning in the workplace. Advance in Health Science Education (2014) 19: 435-456.

Havens, DS, Wood, SO \& Leeman, J. 2006. Improving nursing practice and patient care. Journal of Nursing Administration, 36(10):463-470.

Hodson-Carlton, KE. 2009. The learning resource centre. In Teaching in nursing edited by DM Billings and DA Halstead. Philadelphia: Saunders. pp. 303-321.

http://www.metaVolution.com/img/fiveDCycle.gif (Accessed 16 April 2011).

Holloway, I \& Wheeler, S. 2002. Qualitative research in nursing. $2^{\text {nd }}$ edition.

Oxford: Blackwell Science.

Holloway, I \&Wheeler, S. 2010. Qualitative research in nursing and healthcare. $3^{\text {rd }}$ edition. Oxford: Wiley-Blackwell.

Kaphagawani NC \& Useh U. 2013.Analysis of Nursing Students Learning Experiences in Clinical Practice: Literature Review.Ethno Med, 7(3):181-185.

Kotzé, W. 2008.Empowering the student of nursing: self-empowerment. In Nurse educators' guide to management edited by W Kotzé. Pretoria: Van Schaik:.185-202.

Levett-Jones, T \& Lathlean, J. 2007. Belongingness: a prerequisite for pre-graduate students' clinical learning. Nurse Education Today, (2008) 8:103-111.

Lincoln, YS \& Guba, EG. 1985. Naturalistic inquiry. San Francisco: Sage.

Lind, C \& Smith, D. 2008. Analysing the state of community health nursing: advancing from deficit to strengths-based practice using appreciative inquiry. Advances in Nursing Science, 31(1):28-41.

LoBiondo-Wood, G \& Haber, J. 2010.Nursing research: methods and critical appraisal for evidence-based practice. $7^{\text {th }}$ edition. New York: Elsevier. 
Meyer, S, van Niekerk, S, 2008. Nurse Educator in Practice. Cape Town: Juta.

Moleki, MM. 2008.Critical care pre-graduate students' experience of clinical accompaniment in Open Distance Learning (ODL): a phenomenological perspective. Master's dissertation. Pretoria: University of South Africa.

Mongwe, RN. 2007. Student nurses' experiences of the clinical field in the Limpopo Province as learning field: a phenomenological study. Doctoral thesis, Pretoria, University of South Africa.

Muller, M. 2011. Nursing dynamics. $4^{\text {th }}$ edition. Sandton: Heinemann. 185-202.

Papathanasiou, IJ, Tsaras, K \& Sarafis,P. 2014. Views and perceptions of nursing students on their clinical learnng environment: Teaching and learning. Nurs Education Today 34 (2014) 57-60.

Polit, DF \& Beck, CT. 2008.Nursing research: generating and assessing evidence for nursing practice. $8^{\text {th }}$ edition. Philadelphia: Lippincott Williams and Williams.

Polit, DF \& Beck, CT. 2012. Nursing Research: Generating and Assessing Evidence for Nursing Practice. $9^{\text {th }}$ edition. Philadelphia: Lippincott Williams and Wilkins.

Reed, J. 2007. Appreciative inquiry: research for change. Thousand Oaks: Sage.

Scheider, Z, Whitehead, D \& Elliot, D. 2007.Nursing and midwifery research: methods and appraisal for evidence-based practice. $3^{\text {rd }}$ edition. Sydney: Elsevier.

Shendell-Falik, N, Feinson, M, and Mohr, BJ. 2007. Enhancing patient safety: improving the patient handoff process through appreciative inquiry. Journal of Nursing Administration, 37(2) 95-104.

South Africa. 2005. Nursing Act, 33 of 2005. Pretoria: Government Printer.

South African Nursing Council (SANC). 1985. SANC Regulation R425 leading to registration as a Nurse (General, Psychiatry and Community) and Midwife. Pretoria: SANC.

Sundler, AJ, Bjork,M, Bisholt,B, Ohlsson, U, Engstrom, AK \& Gustafsson, M. 2014. Student nurses experiences of the clinical learning environment in relation to the organization of supervision: A questionnaire survey. Nurse Education Today 34 (2014) 661-666.

Stefaniak, K. 2007. Discovering nursing excellence through appreciative inquiry. Nurse Leader, vol 5 (2):42-46.

Stokes, LG \&Kost, GC. 2009. Teaching in the clinical setting. In Teaching in nursing edited by DM Billings and JA Halstead. Philadelphia: Saunders:283-297.

Yang J. 2013.Korean nursing students' experiences of their first clinical practice.Journal of Nursing Education and Practice, 3(3):128-138. 